\title{
The feasibility of a nuclear renaissance: A cost-benefit analysis of nuclear energy as a source of electricity
}

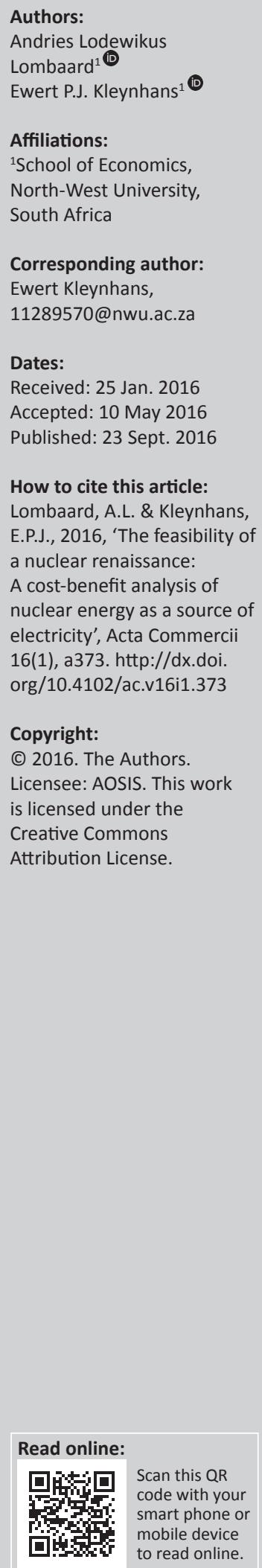

Purpose: This article evaluates a possible global nuclear renaissance in the provision of electrical energy.

Problem investigated: Several countries, such as South Africa, are experiencing problems in the provision of electricity and the maintenance of the infrastructure to answer growing demand. This article investigates an alternative, which was popular in the 1970s and provides clean energy.

Methodology: The study firstly evaluates the main arguments set by anti-nuclear activists critically. It concerns negative public sentiment, human life and environmental endangerment, alternative energy, cost effectiveness and waste disposal concerns. The study focuses on the cost of nuclear power, as the benefits of electricity are assumed homogeneous. The second part of the article reports on an empirical cost-benefit analysis conducted by the authors to estimate the value and likeliness of a nuclear renaissance.

Findings and implications: The empirical analysis indicated that nuclear energy is mostly cost-efficient. The research shows that there might be a slight increase in the use of nuclear power-producing technologies in future.

Originality and value of the research: This study makes a positive contribution to the electrical power and nuclear energy debate. It assesses the possibility of a nuclear renaissance objectively. The environment, global energy shortage and different cost structures of various modes of energy production were considered.

Conclusion: The study concluded that a nuclear renaissance is possible, but that despite the advantages to costs and the environment, this would not yet be statistically significant enough to cause a nuclear renaissance.

\section{Introduction}

This study investigates the possibility of a nuclear renaissance in the world. The use of nuclear power as an energy source was for a long time seen as too dangerous; however, as the need for energy increases, traditional power companies find it ever more difficult to keep up with demand and the sentiment is gradually changing. With the ever increasing threat of global warming, environmentalists are starting to realise that nuclear energy is in fact clean energy, producing no carbon emissions with little fuel demand.

The peaceful use of nuclear energy as part of a country's energy mix is important. Around the world, more and more energy producers are forced to introduce power cuts and load shedding to keep up with the demand (Volkwyn \& Kleynhans 2014). As carbon emissions are threatening the planet, new technologies and improvements develop constantly, offering cost advantages, while the demand for more energy is ever increasing (Greenhalgh \& Azapagic 2009).

A nuclear renaissance can be defined as the noticeable increase in nuclear energy's role in the world's energy mix. In other words, a nuclear renaissance will occur when nuclear power output is again such a prominent part of the global energy mix as it was in the past. During the 1970s, nuclear energy formed $17 \%$ of the global energy mix. Throughout this study, this will be used as the benchmark for a nuclear renaissance (World Nuclear Association 2014).

To assess the viability of nuclear power, both the advantages and disadvantages should be considered. If the benefits of nuclear power outweigh the costs, investment through this form of power generation should be considered and, by implication, a nuclear renaissance could occur. Optimising benefits and mitigating costs of electric energy supply are a prerequisite for optimal 
economic development. When a comparative analysis is done against all other sources of electric power energy, it is seen that nuclear energy has a unique cost-benefit structure. This necessitates a cost-benefit analysis of nuclear energy compared to other sources of electrical energy generation (Clemmer, Freese \& Nogee 2008; Coal Industry Advisory Board 2010).

In such an analysis, economic considerations should not be the only criteria. Safety to people and property, the possibility of nuclear weapons and the effect on the environment should also be considered. This article therefore starts by considering the main arguments against nuclear power and what existing literature has to offer. Next, report is given of the findings of the cost-benefit analysis that was conducted during the current study. The article concludes with a summary and a conclusion of the research.

\section{Opportunities for a nuclear renaissance}

In terms of the sustainability of global energy usage, global demand for electricity currently (2015) exceeds the capacity to produce electricity. World energy demand is growing rapidly and the projected growth in the demand for electricity is almost double that of supply (Clemmer et al. 2008; Coal Industry Advisory Board 2010:58-60; World Nuclear Association 2015e). To ensure international power security that maximises development and helps mitigate environmental concerns, energy supply must be analysed (Clemmer et al. 2008; Coal Industry Advisory Board 2010:58-60; International Energy Agency 2014). In this regard, nuclear energy as a prominent component of the international energy mix has substantial costs and benefits that need to be considered (Grimes \& Nuttall 2010:799-803). There are substantial and compelling arguments for both the resurgence or renaissance of nuclear power production and its abandonment (World Nuclear Association 2015e). This provides the rationale for the current study.

The world is seeking better alternatives to existing energy sources. Fossil fuels and coal are the backbone of the global electricity generation. Coal-driven power is inexpensive because of relatively low setup and operational costs. However, emission costs and rising fuel costs are causing the world to reconsider the reliance on coal in the long run (International Energy Agency 2014:155-177; World Nuclear Association 2015e). The status quo and its inherent shortcomings urge economists and policymakers to do a cost-benefit analysis of alternative energies or 'new' energy sources that can safely be harnessed through technological breakthroughs. This is done in an attempt to evaluate and mitigate the indirect costs of using more traditional, 'dirtier' energies.

Nuclear energy is a prime example of a 'clean' energy source (Exxon Mobil Corporation 2015). Under certain conditions, nuclear power investment can economically be justified. Nuclear energy is cost effective in terms of electricity generation and reaching emission reduction targets (Department for Business Innovation and Skills 2015).
Nuclear power is still a prominent component of the world's electricity mix. By 2010, it provided $12.8 \%$ of global energy. Coal, oil, natural gas and hydropower electricity generation respectively provided $40.4 \%, 4.6 \%, 22.2 \%$ and $16 \%$, and other sources $3.6 \%$ of the world's supply (World Nuclear Association 2015e). Globally, there are 435 nuclear reactors in operation with a total net installed capacity of 374 Gigawatt (GWe) (World Nuclear Association 2013).

Kazlauskaite (2010) and others argue that there is a real possibility of a renaissance of nuclear energy. However, despite optimism pertaining to a nuclear renaissance, the disadvantages should also be considered. These include the costs of power generation, long and expensive licensing procedures, high initial investments and occasional significant hidden nuclear plant construction costs and eventually also considerable decommission costs (Lester \& Rosner 2009:19-30).

Although usually not possible, there is always the concern that nuclear plants might lead to the production of nuclear weapons (Bunn 2006; Pretorius \& Sauer 2014). The possibility of nuclear disasters, changing public sentiment and the costs thereof should be taken into account when considering nuclear energy. The Fukushima Daiichi accident in March 2011 had a significant effect on how nuclear energy risks and costs are perceived (International Energy Agency 2014:190-191).

Research into the viability of nuclear power generation is, however, often biased. There are the supporters with a vested interest in the resurgence of nuclear power, welcoming a renaissance, and those such as Greenpeace, who oppose its growth with a stringent concern for the environment (Exxon Mobil Corporation 2015; Greenpeace 2015). The object of the current study is to provide a scientifically unbiased view of the matter, objectively weighing up the arguments for and against a nuclear renaissance. The following section will investigate the most important arguments against nuclear energy.

\section{Arguments against a nuclear renaissance}

To evaluate the likeliness of a nuclear renaissance, this study commences with an investigation into the five main arguments against nuclear energy. These arguments are derived from Greenpeace (Exxon Mobil Corporation 2015; Greenpeace 2015). Greenpeace is the most influential and outspoken entity against the use of nuclear energy. According to the Social Issues Research Centre (2012) and Murray (2007), there seems to be some doubt in the credibility of research by anti-nuclear organisations such as Greenpeace. The validity of these arguments therefore has to be assessed.

Greenpeace (2015) states that the risk that nuclear energy offers to the environment and to humanity is unacceptably high and the only solution is to end all use of nuclear power. They claim that nuclear energy will just cost too much, 'create tens of thousands of tons of lethal high-level radioactive waste', will lead to dangers in terms of nuclear warfare and will 'result in a Chernobyl-scale accident once every decade'. 
In this section, the literature on cost-benefit analyses done on nuclear power production in the past will also be investigated. The point of departure of the cost-benefit analysis applied in the current study is that the focus should be on the cost side of the scale, as it is assumed that the benefits of energy sources are equal. This concept is known as the Watson's dictum (Donald \& Watson 1971). The most important arguments against nuclear power will now be evaluated.

\section{Argument 1: Public sentiment is against nuclear energy}

The 'green' or anti-nuclear expansion argument emphasises the danger of nuclear leakage from nuclear reactors, fuel and waste storage, as well as possible accidents posing an unacceptable threat to human life and environmental damage (Boulding \& Jarrett 1966). The use of nuclear weapons and accidents, such as Chernobyl and Fukushima Daiichi, reinforced public sentiment against nuclear power. The argument follows that negative sentiment is so strong that it will eventually lead to the abandonment of all nuclear programmes (Van Wyk 2013). Negative sentiment towards nuclear power prohibits further investment in nuclear expansion and leads to statutes and legal frameworks that restrict the use of nuclear power (Kraft \& Rosa 2012:32-35; Nielson 2011; Otruba 1988:88). A prime example is Germany who abandoned their nuclear energy programmes and plants (World Nuclear Association 2015a).

On the one hand, it is alleged that ethical and other considerations by the public sphere cause changes in sentiment that might stop the use of nuclear energy, avoiding a nuclear renaissance (Greenpeace 2015). The main factor influencing sentiment is fear of nuclear accidents. On the other hand, negative sentiment is uncalled for (Serfontein 2015). Research shows that as the public sphere becomes more educated on nuclear energy, negative sentiment decreases, favouring the use of nuclear energy (International Atomic Energy Agency 2005:16-18, 2014:22; World Nuclear Association 2015d). The good overall record of nuclear plants, low carbon emissions and low fuel and operations cost, as well as the high demand for energy all contribute to this (CASEenergy Coalition 2016; World Nuclear Association 2015d).

Research indicates that people harbour a negative sentiment towards the use of nuclear energy in the European Union while, in the United States of America (US), the most prolific user of nuclear energy, people are largely in favour thereof. Surveys are conducted annually and positive sentiments towards nuclear energy are gradually rising. The most important surveys are by the World Nuclear Association (2013, 2014), The Global Public Opinion on Nuclear Issues Report by the International Atomic Energy Agency (IAEA 2005), Eurobarometer Survey by Euroactive, European Commission (2012), The Nuclear Energy Institute(NEI) (2007), Massachusetts Institute of Technology (2009), Zogby International as cited by World Nuclear Association (2013), Bisconti-GfK Roper as cited by the World Nuclear Association (2013) and the 'Gallup poll on energy 2010'. Some environmentalists are also in favour of nuclear energy. Trends show a correlation between the amelioration of sentiment and education, and a weak correlation between the occurrence of a nuclear disaster and sentiment (World Nuclear Association 2015e).

The risk-benefit surveys are important in ascertaining whether sentiment that affects the use of nuclear energy leads to changes in the use of this technology (Harris Interactive 2012). Even when nuclear accidents, such as the Fukushima Daiichi accident, are taken into account, people increasingly believe that nuclear energy usage has more benefits than risks (Bisconti-GfK Roper and 'Gallup poll on energy 2010' as cited by the World Nuclear Association 2015e). This is indicatory that a nuclear renaissance is plausible. The general counter-argument to all anti-nuclear arguments is that ignoring and not using nuclear power is not an option because of the growing demand for energy and the link between the supply of energy and global development (Serfontein 2015). The South African authorities, for example, aim to increase nuclear use to $23 \%$ of their energy mix by 2030 (Department of Energy, South Africa 2015).

The next arguments link closely with the first one. Where the first argument focused on public sentiment, the next focus is on human life and the environment.

\section{Argument 2: Nuclear power, human life and the environment}

It is alleged that because of environmental issues and the danger of nuclear accidents leading to countless deaths, nuclear energy programmes should be abandoned (Greenpeace 2015). Anti-nuclear entities often show horrific pictures and tell tales of a nuclear Armageddon, without much scientific backing (see e.g. Greenpeace 2015). Proponents of nuclear power emphasise that nuclear power generation has virtually no carbon emissions and uses very little fuel, and is therefore regarded as clean energy. Modern generation technological developments render nuclear generation and third generation of nuclear plants safe enough to use (Matzie \& Worral 2004:33-45; Serfontein 2015).

The stance against nuclear power stems mainly from the fact that nuclear energy causes radioactive waste and investment therein could draw attention away from other economic opportunities, especially investments in alternative energy sources with less impact on global warming.

By reviewing the literature about the death tolls associated with the recent Fukushima Daiichi accident, it can be concluded that nuclear energy is not as dangerous as Greenpeace (2008) wishes people to think. According to Holt and Campbell (2014:2), there were no reported deaths related to the use of nuclear energy or nuclear accidents at Fukushima Daiichi. Therefore, the argument that nuclear energy is dangerous for humanity seems to be flawed. Some nuclear scientists complain that the industry is over-regulated, inhibiting nuclear production unjustifiably (Serfontein 2015). This also ensures risk management in excess of the required level. 
Jogalekar (2013) states that only 40 deaths can be attributed to the Chernobyl nuclear accident. Twenty-eight of these deaths are linked directly to the accident and 15 seem to have been caused by cancer resulting from the accident. This accident is deemed the worst nuclear accident in history. It must be noted that Chernobyl used old technology, whereas modern nuclear designs are much safer. It is further stated that no deaths can be linked to the Three Mile Island nuclear incident and no direct deaths were caused by any leakage of nuclear radiation during the Fukushima Daiichi accident. It seems that nuclear energy production is deemed more dangerous than it truly is.

The argument that nuclear energy production should end because it endangers human life will only be logically valid if more humans are killed because of the use of nuclear energy than the number of human lives saved through continued usage of this technology. Research has, however, shown that nuclear energy has saved more lives, in comparison to coalfired power production, and will continue to do so (Hansen \& Pushker 2013). If carbon dioxide emissions can be reduced through the use of nuclear energy, there will even be more lives saved and global warming curtailed. This is because nuclear power is an abundant, low-carbon source and could therefore aid the mitigation of deaths that can be attributed to global climate change and air pollution Jogalekar (2013:1). Hansen and Pushker (2013) have shown that if historical data is used to calculate the number of deaths prevented by the use of nuclear power 1.84 million deaths have been avoided because of such technology. This translates to the 64 gigatons of carbon dioxide that would have been emitted if fossil fuel technology was used as an alternative to nuclear energy.

As per global projections, with the effects of the Fukushima accident taken into account, it was found that the continued use of nuclear power could prevent another 420000 to 7.04 million deaths, and 80 to 240 gigatons less carbon dioxide pollution to the atmosphere, depending on which fuel it replaces (Hansen \& Pushker 2013). By contrast, it is estimated that the large-scale expansion of unconstrained natural gas use, as an alternative to nuclear power, would not mitigate the climate problem and would cause far more deaths than the expansion of nuclear power. These estimates do not include the number of people saved through the medical use of radioisotopes (NECSA 2014).

It must be noted that these facts are somewhat distorted by those supporting a nuclear renaissance. The US Energy Information Administration, for example, states that 'Nuclear energy plants produce no carbon dioxide' (US Energy Information Administration 2015a). This fails to mention that in the uranium mining and enrichment process some fossil fuel and carbon dioxide emissions do occur during transportation to nuclear plants (US Environmental Protection Agency 2015b). It is important to consider the whole picture, but this also applies to other renewable energy sources.

In conclusion, it can be stated that, given the global need for electricity, the use of nuclear energy technology is a viable option, which saves lives and protects the environment. This implies that a nuclear renaissance is possible.

\section{Argument 3: Alternative sources of power production}

Anti-nuclear activists such as Wilson (2012) and Greenpeace (2008) advocate alternative ways of power production. These alternatives include solar power, water power and wind power generation options and it is alleged that it will eventually provide sufficient and safe electrical power. There are, however, still intermittent problems relating to these power generation options.

In the first place, these power production options do not produce power with such regularity and stability as nuclear or coal power and the storage of the generated power from these sources is problematic. Technology related to the storing of power for later use is still largely inadequate. These options are also not cost effective in comparison with coal and nuclear energy production and can often only be used in certain geographical areas. Serfontein (2015) therefore affirms that there are no true substitutes for the production of energy through nuclear technologies. The argument for alternative sources of power production is therefore not totally valid and a nuclear renaissance may still happen.

\section{Argument 4: The cost effectiveness of nuclear power generation}

An important argument is that the production of nuclear power is not cost effective, whereas several studies found that it could be under certain conditions (Schwarz \& Cochran 2013:691-707; Serfontein 2014). Cost-benefit analysis studies of nuclear energy production published in existing literature are limited. Anti-nuclear activists often assume that the construction and decommissioning costs associated with nuclear power plants render it economically unviable (Smith 2011:20). If nuclear technology develops to the stage where its costs are sufficiently less than competing power production technologies, nuclear power will succeed in the long run and a nuclear renaissance may occur. With the progressive deregulation of energy markets, this is possible (IAEA 2014:20-22).

It cannot be outright stated which mode of power production is more economically viable among alternatives. Each method of electrical power production has different cost structures, in different countries, in accordance with the differentiated resource and factor endowments of each country. Nations will invest in power production technologies that are relatively less expensive in their circumstances. Such investment choices are dependent on several intricate factors. Gas and coal-fired power production stations are usually popular investment choices because of their low levels of complexity and lower initial capital costs in comparison with nuclear energy.

The use of nuclear power is, however, expanding as technologies develop. During 2012, twice as many nuclear 
reactors were under construction compared to 2001. It is estimated that the number of new reactors built will increase annually for at least the next decade. The Fukushima Daiichi accident had a negative impact on the new reactors being built, but nuclear power production is becoming economically more viable compared to other sources of power generation and this will lead to an increase in new reactors being built (MIT 2003:37-45, 2009:6; Powers 2012:15-16).

Nuclear power plants have a 'front loaded' cost structure, as they are initially expensive to build, but have relatively low operating costs. This is, however, also the case with renewable energy sources. Compared to the total operating cost, the cost of uranium as nuclear fuel is low. A fact also favouring a nuclear renaissance is that those operating during 2012 declared profits (IAEA 2014:20; MIT 2003:37-45, 2009:6; Powers 2012:15-16).

In terms of the construction of new nuclear plants there is a bigger variation in the economic competitiveness of nuclear power production. Some countries have rich resource deposits that could lead to better cost effective alternatives for nuclear power. Other nations have too low a demand for electrical power to justify the costs of large nuclear plants. Other factors that play a role in the assertion of an investment into nuclear technology are the country's market structure and investment environment. Nuclear power often seems less attractive to private investors operating in free markets. This is mainly because of its 'front loaded' cost structure and the notion that investors wish to receive a return on their investments in their lifetime (IAEA 2014; MIT 2009:6; Powers 2012:15-16).

For the six major electricity production technologies, the research by the International Energy Agency (2014) and Nuclear Energy Agency (2010:9-11) revealed that the localised cost of electricity overlaps $\$ 50$ to $\$ 100$ range for coal, gas and nuclear. It also found that the Fukushima Daiichi accident did not increase the cost of nuclear energy production significantly (IAEA 2014; Powers 2012:15-16). The following section investigates the most important costbenefit studies (IAEA 2014; MIT 2003:37-45, 2009:6; Powers 2012:15-16).

\section{Comparing nuclear cost-benefit studies}

Three important cost-benefit studies are compared in this section, chosen for their size and because their methodology is similar to that conducted in the current study. These studies focus on nuclear power generation and are younger than 10 years.

The first study was conducted by the United Kingdom's Department of Trade and Industry, known as the Nuclear Power Generation Cost-benefit Analysis (this study will be referred to as 'Study 1' below). The second study was done by Canada's Ontario Ministry of Energy, originally called the Cost-benefit Analysis with regard to replacing Ontario's Coal-Fired Generation' (referred to as 'Study 2'), and 'Study $3^{\prime}$ is The New Economics of Nuclear Power, which was conducted by the World Nuclear Association (Department of Trade and Industry, United Kingdom 2007; DSS Management Consultants 2005). Analysing these studies, the basic steps of a cost-benefit analysis were followed, as described by Boardman and Greenberg (2010), and applied as structural filters in this study.

In the first step of such an analysis, the alternative projects are specified and the costs and benefits that would be focused on chosen. In Study 1, the use of nuclear power technology was compared to a scenario where nothing was done. In this 'do nothing' scenario, no new nuclear plants were built and, where nuclear plants were built, they would be replaced by gas-fired plants. Costs in terms of this study were deemed to be those of operating and construction. Benefits chosen were those gained by the operators and the gains to society because of lower carbon emissions.

Study 2 assumed the status quo as a base. Compared to that were an 'all gas option' and a 'stringent control option', where only existing power stations were used. This study described costs vaguely. These costs included the operating costs of nuclear plants as borne by tax payers and capital costs borne by the Ontario Ministry of Energy. The benefits considered seem to be the environmental protection benefits that the public receive.

In Study 3, the costs of constructing new nuclear, gas and coal-fired plants were measured against each other. Costs in this study were also described vaguely. Data from multiple nations were used and therefore it is not clear to whom the benefits of nuclear power production would accrue. It is assumed that the benefits are shared by the involved nations.

In the next step, the impacts are catalogued and measurement indicators are selected. These impacts are then quantitatively specified and monetary values are attached. In Study 1, the impacts catalogue included a reduction in the cost of overall production of electricity, a decreased amount of fuel supply interruptions, a cleaner environment and the impacts of a nuclear accident. These impacts were not quantified as they are deemed to be within the scope of sensitivity. The study assumed a 40-year timeframe. This study considered all the costs from licensing to decommissioning of the plant. An in-depth analysis of the 'do nothing' and the baseline options was included.

The second study considered the costs of power generation in each of the scenarios, health impacts of citizens and air pollution. Other environmental impacts and damages were also studied. This study assumed a 22-year time frame. This study gave a brief summary of the monetary impacts and projected costs of each impact during the lifetime of the nuclear plant.

The third study focused on the economic benefits of using nuclear power generation and meeting world energy needs. The benefits of increased energy security were not factored into the calculations, but observed in isolation. This study 
used a 25-year timeframe. The study utilised a baseline, constructed from the capabilities of nuclear plants in use, and the economic ability of each type of new plant was assessed. This study emphasised the profitability of these plants in liberalised international energy supply markets.

To obtain realistic present values, future estimates of all costs and benefits were discounted and finally the value of each alternative production mode was determined. In Study 1, a discount rate of $3.5 \%$ was used for the first 30 years, and thereafter a discount rate of 3\%. Study 2 did not apply any definite discount rate and net present values were determined for all the tested options. An 'omnibus of international standards' was created by Study 3 through the use of various discount rates for national markets. These discount rates varied between $2.5 \%$ and $10 \%$.

Finally, a sensitivity analysis was performed to ensure that the research results were correct and took all the relevant facts and figures into consideration. In the first study, various sensitivity analyses were done, which included provisions for variations in fossil fuel prices, nuclear power input costs and various risk factors with respect to nuclear accidents. Study 2 indicated that economic benefits could vary much because of changes in the social discount rate and the economic value placed on preventing deaths stemming from air pollution. Study 3 took various discount rates and capital costs into consideration.

When all these estimates are concluded, an optimal investment option can be chosen. Study 1 recommended the continuation of nuclear power generation, as long as the emphasis on low carbon emissions persists. The study concluded that new nuclear power production is economically viable (Department of Trade and Industry, United Kingdom 2007). Of the four parameters analysed by Study 2, it was concluded that nuclear and gas options seemed to yield the greatest benefits (DSS Management Consultants 2005). Study 3 found that nuclear power production is economically viable and necessary because of energy security problems (World Nuclear Association 2005).

The comparison of these studies reflects the economic viability of nuclear power and necessitates more attention on the costs of nuclear power production. These studies all focused on the costs of nuclear power. In line with the costs specified by Gonyeau (2006), attention should also be paid to fuel, new plant capital, operational and maintenance, waste disposal and decommission costs.

With regard to nuclear fuel, Study 1 found that nuclear fuel, especially uranium, represents only a small fraction of production costs. The study was not sensitive to the raw costs of uranium. The second study did not specifically address the issue of uranium enrichment, but historical data was used to ascertain fuel costs. Study 3 offers a comprehensive overview of nuclear fuel costs. The costs of the full fuel cycle were taken into account, also factoring in the costs of nuclear waste management.
The first study indicated that the capital costs associated with the construction of new nuclear plants is largely uncertain because of varied costs of construction, construction times and costs of capital. Study 2 used historic data to estimate capital costs. In the third study, various nuclear disasters and the cost of engineering and labour were taken into account. This study used overnight costs, which do not include interest and financing costs.

With regard to operational and maintenance costs of nuclear power plants, Study 1 took overall and operational costs per MWh produced into account. Study 2 used historic data and it not clear whether the capital costs included the costs of uranium enrichment. Study 3 was again the most thorough and complete. It determined operational costs and noted that efficiency of global power producers increased through the liberalisation of international energy markets.

Studying waste disposal costs, Study 1 used geographic depositories as waste control and added a long-term cost stream to handle waste in the analysis. Study 2 did not provide adequate information about nuclear waste disposal and Study 3 added waste disposal costs to the analysis as part of the fuel production cycle.

Finally, Study 1 took decommissioning and decontamination costs into account, Study 2 did not mention decommissioning costs and Study 3 added decommissioning costs to their analysis.

Assessing the overview given above, it seems that Study 1 offers the strongest model for cost-benefit analysis. This is mainly because of a lack of accounting for decommissioning costs, waste disposal, discount factors and description of costs and benefits observed in Study 2 and Study 3. Study 1 made conservative estimates. Study 3 failed to take the benefits of lower carbon dioxide into account. Study 2 does not offer a very robust model. It does not give any acknowledgement to decommissioning and nuclear waste removal costs and overemphasises the benefits of using nuclear power in terms of environmental protection. From these models, it can be seen that there is great uncertainty with regard to the costs and benefits of nuclear power generation.

From literature and the studies above, it can be derived that the argument that nuclear power production is not economically viable, is invalid. There would be some situational sets where nuclear energy is not the best option, but nuclear power stations currently in operation do render profits and new nuclear power stations might be economically viable.

\section{Argument 5: Nuclear waste disposal}

Proponents against nuclear power see the disposal of nuclear waste as insurmountable. Internationally, it is accepted that geological disposal is the best method, but there is no consensus on waste disposal. Anti-nuclear activists insist that nuclear waste cannot be adequately and cost effectively dealt 
with. Those who advocate the use of nuclear energy state that nuclear waste can be controlled and that the risks attached to nuclear waste can be justified because of the immense benefits attached to power generation (Coertze 2011). Nuclear waste is dangerous, but in the process of electricity generation there is very little waste generated compared to other sources of energy. The World Nuclear Association indicates that that worldwide there is only $10000 \mathrm{~m}^{3}$ of high-level waste produced (World Nuclear Association 2015b). Annually, approximately $200000 \mathrm{~m}^{3}$ low and intermediate level waste is produced. These figures are low when put into perspective with the waste produced annually by European countries. These countries produce about approximately 300 million tons of toxic waste annually. Of this, only $81000 \mathrm{~m}^{3}$ is nuclear waste. Even if waste produced by nuclear energy was large, it might still be worth it when the numbers of developmental possibilities that are attached to nuclear energy are considered (Wilson 2012; World Nuclear Association 2015c).

Those opposing nuclear energy hold the belief that nuclear waste is so dangerous that the world should stop all uses of nuclear generation. Greenpeace, for example, describes nuclear waste as the 'untamed demon of nuclear power'. There is concern that no nuclear waste around the world is stored in permanent repositories and that the costs of handling nuclear waste make nuclear energy economically unviable. Of waste that has been made, only $25 \%$ does not lie in temporary storage, but that is fuel that has been recycled and could be used again (Weyler 2008; Wilson 2012).

In terms of waste, it becomes a question of risk versus benefits. It is undeniable that waste is a problem, but it is also possible that it is a risk worth taking to meet the world's energy needs. With new technological advances improving the utilisation and disposal of nuclear waste accounted for, nuclear waste is not a strong enough argument against the implementation of a nuclear energy.

\section{Summary of the five arguments}

This literature review does not offer a definite indication that a nuclear renaissance will occur; however, given these arguments, it is possible. Sentiment towards nuclear energy seems to be improving over time and there is reason to assume that as people are increasingly informed about nuclear power their sentiment will improve. It was shown that the use of nuclear power technologies have not only saved more lives than were lost in nuclear accidents, but will continue to save lives if used. Sources of renewable energy cannot be seen as substitutes for nuclear power because of difficulties in generating power consistently and problems relating to the storage of electricity. It was not proven that new nuclear plants are economically unviable and it was shown that existing nuclear plants operate at a profit. It was found that the dangers of nuclear waste need not exclude the possibility of more nuclear generation. It is, however, not possible to state that nuclear energy will again reach $17 \%$ of the global energy mix benchmark. Overall, one could at least state that a nuclear renaissance is plausible in the next 30 years.

\section{Empirical analysis: cost-benefit analysis of nuclear power Introduction}

The literature indicated that economic viability of nuclear power production is a key requirement of a nuclear renaissance. In this section, a report is given of a cost-benefit analysis of nuclear power production, conducted for the current study, which offers some insight into this argument. If this analysis shows that nuclear energy is cost effective, it might be a strong argument that nuclear energy will remain a relevant part of the global energy mix. Alternatively, the analysis could indicate that nuclear energy is not cost effective and disprove the notion of a nuclear renaissance. The same logic would apply if it is found that nuclear energy is significantly less expensive than other sources of power production.

\section{Cost-benefit analysis: theoretical aspects}

A cost-benefit analysis is a systematic process with the goal of calculating and comparing net benefits and costs of projects, decisions or policy (Brown \& Campbell 2015). Cost-benefit analysis attempts to determine the feasibility of an investment and it forms a systematic empirical method of providing a basis of comparison for projects (Nagendram et al. 2012). It is an analysis showing the expected balance of costs and benefits and is often used to predict whether the costs of a policy outweigh its benefits. This implies that it is an effective tool to calculate a project's opportunity costs. Assuming the analysis in question is accurate, changing the status quo by implementing the option with the lowest cost-benefit ratio, can improve efficiency. This can be a difficult task especially when unquantifiable factors are included in the analysis (Nagendram et al. 2012:37).

This study links closely with the literature review above. As was noted, the Watson's dictum is accepted regarding all benefits of power generated equivalent and focuses exclusively on cost comparisons. The steps followed are also similar to the Boardman and Greenberg guidelines (2010) followed in the analysis in Section 3.4.1 and the cost specifications of the Gonyeau (2006) framework. The most important assumptions made were that all costs can be quantified accurately, and all options can be substituted and traded freely (Ackerman 2008:3-11).

\section{Shortcomings of this cost-benefit analysis}

The US, which is the most prolific producer of nuclear technology, is the best nation to do this analysis on to obtain an estimation for the rest of the developed world. Results in terms of the US cannot, however, be directly transferred to other nations.

Use of Watson's dictum can also be criticised as it predates the concerns of global warming. As nuclear power plants produce relatively little carbon dioxide as part of the production process, not accounting for environmental factors 
is therefore a negative bias against a nuclear renaissance. To adjust the analysis to carbon control costs, this externality was added to the cost structure of power plants. This cost benefit also does not take resource availability, in terms of the fuel needed, into account.

Various interest rates will have a marked effect on the viability of power plants (Serfontein 2014), but this was not considered. The financing costs are not included in the calculation of capital costs; the capital costs are therefore called the 'overnight costs'; which implies that the power plant appeared fully constructed overnight. Other critiques include the problem of quantifying unquantifiable costs or benefits, isolating costs and benefits, the assumptions of perfect substitutions, keeping long-term figures within a reasonable timeframe and problems with accurate measurement.

\section{Explanation of the empirical method}

Cost-benefit analyses seem the most logical and are often applied to these kinds of studies. This methodology seems to be the standard. The Boardman and Greenberg (2010) guidelines flow from well-documented methodology on the cost-benefits peer-reviewed analysis.

To enable comparison of future income and cost streams for the period of operation, all monetary values had to be converted to their current values, using a discount rate. A rate of $5 \%$ was used for nuclear power production by the government sector and $10 \%$ for private investments (Department of Finance and Deregulation, Australia 2009:1-3). This allows for some sensitivity analysis, makes adequate provision for high overnight capital costs associated with the building of new nuclear plants, and also correlates with studies cited in the literature review. The general decision rule states that a policy or project should be implemented if the net present value is positive, and where there is a choice between alternatives, the project with the highest net present value should be chosen.

The data was mainly sourced from the World Nuclear Association (2015f) as it contains the most up-to-date data available. Data for South Africa was not available for the purposes of this study, because of the sensitivity of nuclear data (Ballack 2010). Therefore, data of the US, as published in 2015, was predominantly used. Data from this source might be seen as biased, but it is in most cases the only data available. Other sources are usually treated in secrecy and/or are very old (Ballack 2010). All prices are in United States dollars (US\$) and the common power unit c/Kwh (cent per kilowatt hour).

\section{Analysis of the cost structure}

The costs of nuclear power generation were analysed similar to the Gonyeau (2006) guidelines followed in Section 3.4.1 above.

\section{Fuel costs}

The current uranium spot price of $1 \mathrm{~kg}$ of uranium reactor fuel during 2013 is given in Table 1:
TABLE 1: Cost of nuclear fuel.

\begin{tabular}{lcc}
\hline Nuclear fuel & Unit or conversion & Price in US\$ \\
\hline Uranium & $8.9 \mathrm{~kg} \mathrm{U308 \times \$ 130}$ & 1160 \\
Conversion & $7.5 \mathrm{~kg} \mathrm{U} \times \$ 11$ & 83 \\
Enrichment & $7.3 \mathrm{SWU} \times \$ 120$ & 880 \\
Fuel fabrication & Per kg & 240 \\
\hline Total & & $\mathbf{2 3 6 0}$ \\
\hline
\end{tabular}

Source: World Nuclear Association 2013 \& 2015c

TABLE 2: Overnight capital cost options.

\begin{tabular}{|c|c|c|c|}
\hline \multirow{2}{*}{$\begin{array}{l}\text { Overnight capital costs in c/kWh } \\
\text { First unit produced }\end{array}$} & \multicolumn{3}{|c|}{ Cost per output capacity of plant } \\
\hline & $\$ 1200 \mathrm{~kW}$ & $\$ 1500 \mathrm{~kW}$ & $\$ 1800 \mathrm{~kW}$ \\
\hline $\begin{array}{l}\text { Plant lifespan: } 40 \text { years } \\
\text { Years to build: } 7\end{array}$ & 5.3 & 6.2 & 7.1 \\
\hline $\begin{array}{l}\text { Plant lifespan: } 60 \text { years } \\
\text { Years to build: } 5\end{array}$ & 4.3 & 5.0 & 5.8 \\
\hline \multicolumn{4}{|l|}{ 4th unit produced } \\
\hline $\begin{array}{l}\text { Plant lifespan: } 40 \text { years } \\
\text { Years to build: } 7\end{array}$ & 4.5 & 4.5 & 5.3 \\
\hline $\begin{array}{l}\text { Plant lifespan: } 60 \text { years } \\
\text { Years to build: } 5\end{array}$ & 3.7 & 3.7 & 4.3 \\
\hline \multicolumn{4}{|l|}{ 8th unit produced } \\
\hline $\begin{array}{l}\text { Plant lifespan: } 40 \text { years } \\
\text { Years to build: } 7\end{array}$ & 4.2 & 4.2 & 4.9 \\
\hline $\begin{array}{l}\text { of Plant lifespan: } 60 \text { years } \\
\text { Years to build: } 5\end{array}$ & 3.4 & 3.4 & 4 \\
\hline
\end{tabular}

Source: World Nuclear Association 2013

This study assumes 45000 Megawatt day per ton (MWd/t) for the efficient burn-up rate for uranium. Given this, 360000 kilowatt hours ( $\mathrm{kWh}$ ) electrical power is produced per kilogram of uranium used and fuel costs per kilowatt amount to $0.66 \mathrm{c} / \mathrm{kWh}$ for the production of new fuel (World Nuclear Association 2013, 2015c). It must be taken into account that some of the fuel used in the process is recycled. These fuel recycling costs are $0.1 \mathrm{c} / \mathrm{kWh}$, amounting to a total fuel cost of $0.76 \mathrm{c} / \mathrm{kWh}$. (Fuel cost $\$ 2360$ per $\mathrm{kg}$, which can generate $360000 \mathrm{kWH} ; \$ 2360 / 3600000 \mathrm{kwh}=0.66 \mathrm{c} / \mathrm{kWH}$. Adding to that some recycling cost at $0.1 \mathrm{c} / \mathrm{kWH}$ results in a $0.76 \mathrm{c} / \mathrm{kwh}$ fuel cost in the proper units).

\section{Overnight capital costs}

Various overnight capital costs used to ascertain the costs of power production through nuclear technology are given in Table 2. Estimation of these figures assumes production capacity of $90 \%$ when plants run continuously. These figures are comparable to the operational costs of coal and gas plants that are estimated at 3.5 and $4.5 \mathrm{c} / \mathrm{kWh}$, respectively. If carbon control costs of $1.5 \mathrm{c} / \mathrm{Kwh}$ and $1 \mathrm{c} / \mathrm{Kwh}$ are added respectively to the capital costs for coal and gas plants, nuclear plants would be absolutely more competitive. Literature shows operating costs of nuclear plants built after the eighth plant with a lifespan of 60 years will take 5 years to build and have a power output capacity of $1500 \mathrm{~kW}$. This was the value used in the current study and overnight capital costs were therefore taken as 3.4 c/Kwh (World Nuclear Association 2013).

\section{Maintenance and operating costs}

The World Nuclear Association sets the cost of maintenance and operating nuclear plants at $0.6 \mathrm{c} / \mathrm{Kwh}$. This includes systemic costs and external costs, normally used in these types of analyses (World Nuclear Association 2013). 


\section{Waste control costs}

The given costs for nuclear waste disposal vary between 0.3 and $0.1 \mathrm{c} / \mathrm{Kwh}$ (Serfontein 2015; World Nuclear Association 2013). An average cost of $0.2 \mathrm{c} / \mathrm{Kwh}$ was used in order to calculate the cost of nuclear power in this study.

\section{Decommissioning costs}

Nuclear plant decommissioning costs are estimated to be between $9 \%$ and $15 \%$ of the initial capital costs. This amount had to be discounted and then amounted to a relatively small percentage of the generation costs. Estimated decommissioning costs for the US are, on average, $0.15 \mathrm{c} / \mathrm{kWh}$. In relative terms, this is less than $5 \%$ of the total costs of electricity produced.

\section{Empirical findings within the context of the literature study}

This study estimated the costs of nuclear power generation to be $4.35 \mathrm{c} / \mathrm{kwh}$. This figure is the sum the five cost components. When discount rates of $5 \%$ and $10 \%$ are respectively added for governmental and private investment to give the real costs of power production, the final benefit per cost is obtained. This is done to ensure that the front-loaded investment structures of nuclear power plants are taken into account. At a 5\% discount rate, total cost of nuclear production, per benefit, is approximately $4.675 \mathrm{c} / \mathrm{kWh}$. Given a $10 \%$ discount rate, nuclear power production will cost approximately $7.650 \mathrm{c} / \mathrm{kWh}$.

These results should be put within context with the generating price of other methods of power generation. These methods include traditional and modern coal power generation, onshore wind and gas power production. The average cost of all the possible methods of generating power for the US across all methods was 6.2 and $8.3 \mathrm{c} / \mathrm{Kwh}$ at $5 \%$ and $10 \%$ discount rates. The corresponding standard deviations are 1.42 and 1.04 for these discount rates, respectively. Internationally, power production methods totalled an average of 7.7 and $10.3 \mathrm{c} / \mathrm{kWh}$ with a $5 \%$ and $10 \%$ discount rate. In this case, there was standard deviation of 2.7 and 3.6, respectively. These values have to be interpreted.

In all accounts, nuclear power production costs, in the US and internationally, are not statistically significantly lower. If the production costs of nuclear plants were more than two standard deviations cheaper than the overall average cost of power production, nuclear power generation costs would be significantly different from those of other methods of electrical power production. From the results obtained, no significant conclusion about a nuclear renaissance can be made from the findings, as it falls in the so-called zone of indecision. It should be stated that, in the US, nuclear is a slightly less expensive than other methods of power generation. The total cost of nuclear production is in a range where no real increase or decrease in the use of nuclear power as part of the global energy production mix is expected, even though nuclear generation costs less in absolute terms. The costs are not too high to abandon nuclear, but also not so low that it justifies switching over totally.
The empirical analysis revealed that nuclear energy is the least expensive form of power production in the US on the $5 \%$ level and the second least expensive on the $10 \%$ discount level. On a basis of costs per output, these figures could be indicative that nuclear energy will increasingly be used in the future to produce power in the US. As these costs are, however, not statistically significantly cheaper, it is likely that only a small increase in the use of nuclear power will follow and that nuclear use will not reach $17 \%$ of the global energy mix. In the foreseeable future, no nuclear renaissance is likely to occur on account of the economics of nuclear energy, even if there is a slight increase in the use of nuclear energy. This is in line with the literature provided on argument 4 above.

With slight variation, the same was found for other countries. The costs of power production internationally were studied for the most prolific producers of nuclear power, which included Belgium, the Czech Republic, France, Germany, Hungary, Japan, Korea, the Netherlands, Slovakia, Switzerland, China, USA and Russia, and the findings differ for each country.

\section{Summary and conclusions}

This study set out to assess objectively whether a nuclear renaissance is plausible. As the universal move to clean energy sources becomes increasingly important, it is important to reconsider the use of nuclear, as it might be cost efficient. Nuclear energy is regarded as clean energy, having no carbon emissions in the atmosphere, and is low on fuel demand.

The authors set the hypothesis that a nuclear renaissance is likely. The result of this study has shown that although there might be a slight increase in the use of nuclear power technologies in the future, this increase would not be enough to cause a nuclear renaissance.

The main arguments against nuclear energy were derived from those opposing nuclear use. Their main arguments affirm that a nuclear renaissance is unlikely because of the negative public sentiment, endangerment to human life and environment, the availability of alternatives, cost effectiveness issues and waste disposal concerns.

These arguments were first addressed in the literature overview. The fourth argument on costs was analysed through a literature review and empirically tested. This study focused especially on costs and made the assumption that all energy benefits are homogeneous. In this regard, the research question whether nuclear power is sufficiently cost effective, both in the US and internationally, to offset the negative impacts of antinuclear sentiment and arguments, found that nuclear energy is a relatively inexpensive method of power production compared to traditional and modern power production from coal, onshore wind power production and natural gas.

The findings of the cost-benefit analysis are in line with other forecasts for nuclear power generation. The literature review had shown that nuclear energy power output will increase by 
58\% until 2035 (International Energy Agency 2014:190-191; World Nuclear Association 2015e). It was found that nuclear power is less expensive in most cases. It is, however, not less expensive beyond the two standard deviation thresholds to adhere to the statistical significance criteria. Nuclear power will only remain relevant as part of the global energy mix and it is unlikely that a nuclear renaissance will occur.

The results of this study are summarised in Table 3. This table shows that most arguments indicate that a nuclear renaissance is possible. It was also found through the cost-benefit analysis that nuclear power technology is cost effective when compared to other sources of electrical power. Given this, the lives saved by the use of nuclear power generation, the developmental possibilities unlocked through such power generation and the environmental benefits from the use of nuclear power as shown in the literature overview, it is reasonable to support the occurrence of a nuclear renaissance.

Regarding cost efficiency, it is worth taking note of the fact that it was found throughout this study that although nuclear power production is cost effective, these plants were found not to be cost effective enough to warrant a nuclear renaissance. It is estimated that nuclear power production would increase, but that such increase would not likely be enough to reach the nuclear renaissance benchmark of $17 \%$ of the global energy mix during the next 30 years. The occurrence of a nuclear renaissance could not be ruled out by this as the majority of arguments indicated that it is possible.

Policy recommendations would differ from nation to nation, because of geographical, labour and cost considerations that differentiate cost effectiveness of nuclear power plant usage between nations. It is, however, recommended that where nuclear power can be produced relatively cost efficiently, such investment in nuclear power should be considered. This is because of the environmental friendliness of nuclear technology, improving public sentiment over time and the problems of other sources of power production. With such policy decisions, the natural resources of a given country and global environmental concerns should be accounted for. For the US, a focal point of this study and the most prolific user of nuclear power generation technologies, increased investment into nuclear power is advised.

Through a cost-benefit analysis and the weighing up of nuclear renaissance arguments, it was found that the occurrence of a nuclear renaissance is plausible and investment expansion policy is recommended for nations where nuclear power is cost effective. Although this study concluded that a

TABLE 3: Summary of nuclear renaissance arguments.

\begin{tabular}{lccc}
\hline Argument & $\begin{array}{c}\text { Anti- } \\
\text { renaissance }\end{array}$ & Neutral & $\begin{array}{c}\text { Pro- } \\
\text { renaissance }\end{array}$ \\
\hline 1. Public sentiment & - & - & $\mathrm{X}$ \\
2. Human life and the environment & - & - & $\mathrm{X}$ \\
3. Alternative sources of power & - & - & $\mathrm{X}$ \\
4. Cost-effectiveness & $\mathrm{X}$ & - & - \\
5. Waste disposal & - & $\mathrm{X}$ & - \\
\hline
\end{tabular}

Source: Authors' own work nuclear renaissance is unlikely, it was found that as public sentiment improves over time, nuclear power is relatively safe and that neither the costs nor waste disposal concerns prohibit the possibility of a nuclear renaissance from occurring.

\section{Acknowledgements}

The editor and reviewers are thanked for their contribution to this article. Their helpful comments and suggestions are acknowledged. They assisted in improving the manuscript and ameliorate the quality to a higher level.

\section{Competing interests}

The authors declare that they have no financial or personal relationships which may have inappropriately influenced them in writing this article.

\section{Authors' contribution}

A.L.L. formulated the concept and did the original research. At the time of the study and finalisation of the manuscript A.L.L. was a research associate at North-West University (South Africa). E.P.J.K. was the project leader. Assisted in the interpretation of the empirical findings and development of the manuscript. E.P.J.K. wrote the article and finalised the manuscript for publication.

\section{References}

Ackerman, F., 2008, Critique of cost-benefit analysis, and alternative approaches to decision-making, Friends of the in Earth England, London.

Ballack, P.A., 2010, 'Framework for the cost of policy implementation of the South African Nuclear Expansion Program', M.Eng. dissertation, Unpublished, North-West University, Potchefstroom.

Boardman, A.E. \& Greenberg, D.A., 2010, Cost benefit analysis: Concepts and practise, 3rd edn., Pearson Prentice Hall, Upper Saddle River, NJ.

Boulding, K.E. \& Jarrett, H. (eds.), 1966, The economics of the coming spaceship earth Environmental quality in a growing economy, Harper and Row, New York.

Brown, R. \& Campbell, H., 2015, Benefit-cost analysis, Cambridge University Press, New York.

Bunn, M., 2006, 'A mathematical model of the risk of nuclear terrorism', Annals of the American Academy of Political and Social Science 607(1), 103-120. http://dx.doi. org/10.1177/0002716206290182

CASEnergy Coalition, 2016, Clean, viewed 12 July 2016, from http://casenergy.org/ nuclear-benefits/clean/

Clemmer, S., Freese, B. \& Nogee, A., 2008, Coal power in a warming world, Union of Concerned Scientists Press, Cambridge, MA.

Coal Industry Advisory Board, 2010, Power generation from coal, OECD International Energy Agency, Paris, pp. 58-60.

Coertze, R.J., 2011, 'The regulation of radioactive waste in South Africa', LLM dissertation, North-West University, Potchefstroom.

Department for Business Innovation and Skills, United Kingdom, 2015, Nuclear power viewed 12 July 2016, from http://webarchive.nationalarchives.gov.uk/ 20090609003228/http://www.berr.gov.uk/files/file39525.pdf

Department of Energy, South Africa, 2015, Nuclear procurement process update, Media Statement, Pretoria, South Africa.

Department of Finance and Deregulation, Australia, 2009, Best practice regulation guidance note decision rules in regulatory cost-benefit analysis, Department of Finance and Deregulation, Sydney.

Department of Trade and Industry, United Kingdom, 2007, Nuclear power generation cost benefit analysis, Department of Trade and Industry, London.

Donald, E. \& Watson, M.D., 1971, Goals of a cost benefit analysis in electrical power generation, Bio-Medical Division of the Lawrence Livermore Laboratory, University of California, Livermore, CA.

DSS Management Consultants, 2005, Cost benefit analysis: Replacing Ontario's coa fired electricity generation, Ontario Ministry of Energy Ontario Ministry of Energy Toronto, Ontario.

Euroactive, 2012, Standard eurobarometer, European Commission, Brussels, viewed 12 July 2016, from http://ec.europa.eu/public_opinion/archives/eb/eb78/eb78_ first_en.pdf 
Exxon Mobil Corporation, 2015, The outlook for energy: A view to 2040, Exxon Mobil Corporation, Irving, TX.

Gallup, 2010, Gallup poll on energy, viewed 12 July 2016, from http://www.gallup. com/poll/2167/energy.aspx

Gonyeau, J., 2006, Cost comparison for nuclear vs. coal, viewed 12 July 2016, from http://www.nucleartourist.com/basics/costs.htm

Greenhalgh, C. \& Azapagic, A., 2009, 'Review of drivers and barriers for nuclear power in the UK', Environmental Science and Policy 12(7), 1052-1067. http://dx.doi. org/10.1016/j.envsci.2009.07.006

Greenpeace, 2008, Nuclear power undermining climate protection, Greenpeace Publishing, Amsterdam.

Greenpeace, 2015, End of a nuclear age, viewed 12 July 2016, from http://www. greenpeace.org/international/en/campaigns/nuclear/

Grimes, R. \& Nuttall, W., 2010, 'Generating the option of a two-stage nuclear renaissance', American Association for the Advancement of Science 329(5993), 799-803. http://dx.doi.org/10.1126/science.1188928

Hansen, J.E. \& Pushker, A., 2013, Prevented mortality and greenhouse gas emissions from historical and projected nuclear power, NASA Goddard Institute for Space Studies and Columbia University Earth Institute, New York.

Harris Interactive, 2012, One year post Fukushima, Americans are divided about the risks of nuclear power, viewed 12 July 2016, from http://www.theharrispoll.com/ search?keywords=One+year+post+Fukushima\%2C+Americans+are+divided+abo ut+the+risks+of+nuclear+power

Holt, M. \& Campbell, R., 2014, Fukushima nuclear disaster, Congressional Research Service Congressional Research Service of the United States of America, Washington.

International Atomic Energy Agency (IAEA), 2005, Global public opinion on nuclear issues and the International Atomic Energy Agency, Toronto: GlobeScan Incorporated.

International Atomic Energy Agency (IAEA), 2014, Climate change and nuclear power, pp. 20-22, IAE Publishers, New York.

International Energy Agency, 2014, World energy outlook 2014, OECD, Paris.

Jogalekar, A., 2013, Nuclear power may have saved 1.8 million lives otherwise lost to fossil fuels, may save up To 7 million more, South African Nuclear Energy Corporation, Johannesburg.

Kazlauskaite, Z., 2010, A new nuclear power plant in Lithuania: Cost-benefit analysis, University of Aarhus, Aarhus.

Kraft, M.E. \& Rosa, E., 2012, Public reactions to nuclear waste: Citizens' views of repository siting, Duke University Press, Durham, NC.

Lester, R.L. \& Rosner, R., 2009, 'The growth of nuclear power: Drivers and constraints', Daedalus 4, 19-30. http://dx.doi.org/10.1162/daed.2009.138.4.19

Massachusetts Institute of Technology (MIT), 2003, The future of nuclear power, MIT University Press, Massachusetts, MA.

Massachusetts Institute of Technology (MIT), 2009, Update of the MIT 2003 the future of nuclear power, MIT University Press, Massachusetts, MA

Matzie, R. \& Worral, A., 2004, 'The AP1000 reactor - The nuclear renaissance option', Nuclear Energy 43(1), 33-45. http://dx.doi.org/10.1680/nuen.43.1.33.36387

Murray, J., 2007, 'Greenpeace defends controversial Apple research', viewed 12 July 2016, from http://www.businessgreen.com/bg/blog-post/1810659/greenpeacedefends-controversial-apple-research

Nagendram, N., Rani, T., Kumar, T. \& Reddy, Y., 2012, 'Applications of linea programming on optimization of cool freezers', International Electronic Journal of programming on optimization of cool free
Pure and Applied Mathematics 5(1), 37.

Nielson, 2011, 'Events in Japan impact nuclear power debate in Italy', viewed 12 July 2016, from http://www.nielsen.com/us/en/insights/news/2011/events-in-japanimpact-nuclear-power-debate-in-italy.html

Nuclear Energy Agency, 2010, Projected costs of generating electricity, NEA Press, Paris.

Nuclear Energy Institute (NEI), 2007, 'Survey reveals gap in public's awareness of nuclear energy's role in reducing greenhouse gases', viewed 12 July 2016, from

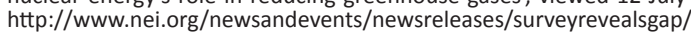

Otruba, T., 1988, 'Local nuclear-free zone legislation: Force of law of expressions of political sentiment', viewed 12 July 2016, from http://heinonline.org/HOL/Landin gPage?collection=journals\&handle=hein.journals/usflr22\&div=25\&id=\&page
Powers, A., 2012, Nuclear power: The safe and green alternative, Indiana University Press, Bloomington, IN.

Pretorius, J. \& Sauer, T., 2014, 'The nuclear security discourse: Proliferation vs disarmament concerns', South African Journal of International Affairs 21(3), 321-334. http://dx.doi.org/10.1080/10220461.2014.965273

Schwarz, P. \& Cochran, J., 2013, 'Renaissance or requiem: Is nuclear energy cost effective in a Post-Fukushima World?' Contemporary Economic Policy 31(4), 691-707. http://dx.doi.org/10.1111/j.1465-7287.2012.00341.x

Serfontein, D.E., 2014, 'Nuclear power more profitable than coal if funded with low cost capital: A South-African case study', Proceedings of the HTR 2014, Paper HTR 2014-1-11183, Weihai, Shandong Province, China, 27 - 31 October 2014.

Serfontein, D.E., 2015, The costs, benefits and development of nuclear energy, personal interviews, School for Nuclear Engineering, North-West University, personal interview
Potchefstroom.

Smith, G., 2011, Nuclear roulette: The case against a 'Nuclear Renaissance', pp. 20-22, International Forum on Globalization, viewed 12 Mar. 2013, from http:// ifg.org/v2/wp-content/uploads/2014/04/

Social Issues Research Centre, 2012, 'The tide turns against Greenpeace', viewed 19 Sept. 2016, from http://www.sirc.org/articles/tide_against_greenpeace.html

South African Nuclear Energy Corporation (NECSA), 2014, Safari-1 research reactor, 50 years of excellence, Annual report, NECSA, Pretoria.

US Energy Information Administration, 2015a, US Energy Information Administration, viewed 12 July 2016, from http://www.eia.gov/energyexplained/index.cfm? page=nuclear_environment

US Environmental Protection Agency, 2015b, Clean energy, US Environmental Protection Agency, viewed 12 July 2016, from http://www.epa.gov/cleanenergy/ energy-and-you/affect/air-emissions.html

Van Wyk, J., 2013, South Africa's nuclear future, Occasional paper no. 150, Governance of Africa's Resources Programme, South African Institute of International Affairs, Johannesburg, South Africa.

Volkwyn, B.J. \& Kleynhans, E.P.J., 2014, 'Die verskaffing van elektrisiteit deur Eskom Die impak van beurtkrag en hoër pryse op die Suid- Afrikaanse ekonomie', SuidAfrikaanse Tydskrif vir Natuurwetenskap en Tegnologie 33(1), viewed 12 July 2016, from http://www.satnt.ac.za/index.php/satnt/article/viewFile/430/2597

Weyler, R., 2008, 'Deep green: Atomic renaissance interrupted', viewed 12 July 2016, from http://www.greenpeace.org.uk/blog/climate/deep-green-atomic-renaissanceinterrupted-20081203

Wilson, L., 2012, 'Nuclear power and alternatives', viewed 12 July 2016, from http:// drlwilson.com/Articles/NUCLEAR\%2OPOWER.htm

World Nuclear Association, 2005, The new economics of nuclear power, OECD Press, WNA, London.

World Nuclear Association, 2013, The economics of nuclear power, updated May 2016, viewed 12 July 2016, from http://www.world-nuclear.org/informationlibrary/economic-aspects/economics-of-nuclear-power.aspx

World Nuclear Association, 2014, The nuclear renaissance, updated September 2015 viewed 12 July 2016, from http://www.world-nuclear.org/information-library/ current-and-future-generation/the-nuclear-renaissance.aspx

World Nuclear Association, 2015a, Nuclear power in Germany, updated 6 July 2016 viewed 12 July 2016, from http://www.world-nuclear.org/info/Country-Profiles/ Countries-G-N/Germany/

World Nuclear Association, 2015b, Radioactive waste management, updated July 2016, viewed 12 July 2016, from http://www.world-nuclear.org/info/Nuclear2016, viewed 12 July 2016, from http://www.world-nuclea
Fuel-Cycle/Nuclear-Wastes/Radioactive-Waste-Management/

World Nuclear Association, 2015c, Supply of uranium, updated September 2015, viewed 12 July 2016, from http://www.world-nuclear.org/info/Nuclear-FuelCycle/Uranium-Resources/Supply-of-Uranium/

World Nuclear Association, 2015d, US Nuclear Power Policy, updated July 2016 viewed 12 July 2016, from http://www.world-nuclear.org/info/Country-Profiles/ Countries-T-Z/USA--Nuclear-Power-Policy/

World Nuclear Association, 2015e, World energy needs and nuclear power, updated June 2016, viewed 12 July 2016, from http://www.world-nuclear.org/info/ Current-and-Future-Generation/World-Energy-Needs-and-Nuclear-Power/

World Nuclear Association, 2015f, World nuclear power reactors \& uranium requirements, updated 01 July 2016, UK Department of Trade and Industry, Nuclear Power, World Nuclear Association, viewed 12 July 2016, from http:// www.world-nuclear.org/info/Facts-and-Figures/World-Nuclear-Power-Reactorsand-Uranium-Requirements/ 